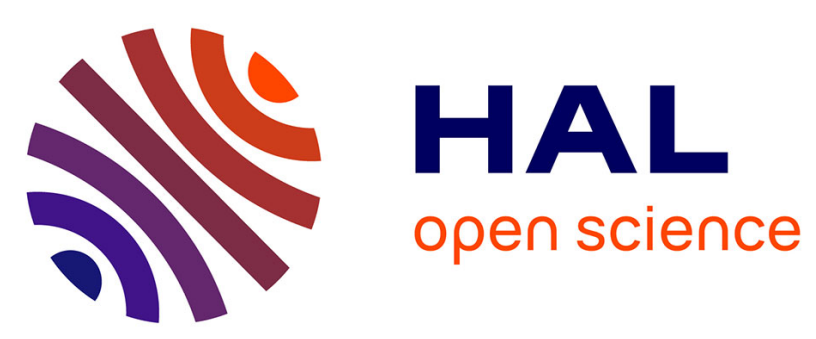

\title{
A numerical study of the evolution of the blast wave shape in rectangular tunnels
}

David Uystepruyst, François Monnoyer de Galland

\section{To cite this version:}

David Uystepruyst, François Monnoyer de Galland. A numerical study of the evolution of the blast wave shape in rectangular tunnels. Journal of Loss Prevention in the Process Industries, 2015, 10.1016/j.jlp.2015.03.003 . hal-01215200

\author{
HAL Id: hal-01215200 \\ https://hal.science/hal-01215200
}

Submitted on 14 Oct 2015

HAL is a multi-disciplinary open access archive for the deposit and dissemination of scientific research documents, whether they are published or not. The documents may come from teaching and research institutions in France or abroad, or from public or private research centers.
L'archive ouverte pluridisciplinaire HAL, est destinée au dépôt et à la diffusion de documents scientifiques de niveau recherche, publiés ou non, émanant des établissements d'enseignement et de recherche français ou étrangers, des laboratoires publics ou privés. 


\title{
A numerical study of the evolution of the blast wave shape in rectangular tunnels
}

\author{
David Uystepruyst ${ }^{\mathrm{a}, \mathrm{b}, *}$, François Monnoyer ${ }^{\mathrm{a}, \mathrm{b}}$ \\ ${ }^{a}$ Univ Lille Nord de France, F-59000 Lille, France \\ ${ }^{b}$ UVHC, TEMPO, F-59313 Valenciennes, France
}

\begin{abstract}
When the explosion of condensed materials occurs in square or circular cross-section tunnel, the subsequent blast wave reveals two patterns: threedimensional close to the explosive charge and one-dimensional far from the explosion. Pressure decays for these two patterns have been thoroughly studied. However, when the explosion occurs in rectangular cross-section tunnel, which is the most regular geometry for underground networks, the blast wave exhibits a third, two-dimensional, patterns. In order to assess the range of these three patterns, several numerical simulation of blast waves were carried out varying the width and the height of the rectangular cross-section as well as the mass of the charge. Laws are presented to localize the transition zones between the $3 \mathrm{D}$ and the $2 \mathrm{D}$ patterns, and between the $2 \mathrm{D}$ and the 1D patterns, as functions of non-dimensional width and height. The numerical results of the overpressure are compared to existing $3 \mathrm{D}$ and $1 \mathrm{D}$ laws. An overpressure decay law is proposed to represent the 2D pattern. Knowing the two transition zones and the overpressure decays within these
\end{abstract}

\footnotetext{
*Corresponding author. Tel.: +33327511980; Fax: +33327511961. E-mail address: david.uystepruyst@univ-valenciennes.fr (D. Uystepruyst).
} 
zones, an algorithm is presented to efficiently predict an overpressure map. This algorithm is validated by comparison with experimental data.

Keywords: Damage assessment for explosions, three-dimensional simulation, blast wave, confined domain, adaptive grid

\section{Nomenclature}

\section{Greek letters}

$\alpha_{x}=100 d_{c} / x$ ratio of the explosive diameter $d_{c}$ to the tunnel hydraulic diameter $d_{H}$, height $H$, width $H$ or $W-H$

$\Delta x \quad$ mesh cell size $(m)$

$\lambda \quad$ mesh wavenumber, $\lambda=m_{c}^{1 / 3} / \Delta x\left(\mathrm{~kg}^{1 / 3} / \mathrm{m}\right)$

$\omega \quad$ constant for Jones-Wilkins-Lee (JWL) equation of state

$\Phi \quad$ tunnel cross-section diameter $(m)$

$\rho \quad$ density $\left(\mathrm{kg} / \mathrm{m}^{3}\right)$

\section{Latin letters}

A tunnel cross-sectional area $\left(m^{2}\right)$

$A, B, C, R_{1}, R_{2}$ constants for the JWL equation of state

$C_{p} \quad$ pressure coefficient $C_{p}=\left(p-p_{0}\right) / p_{0}$

$d \quad$ diameter $(m)$ 
$E \quad$ total specific internal energy, $E=e+\frac{1}{2}\left(u^{2}+v^{2}+w^{2}\right)(J / k g)$

e $\quad$ specific internal energy $(\mathrm{J} / \mathrm{kg})$

$H \quad$ height of the tunnel $(m)$

$L \quad$ length of the tunnel $(m)$

$M \quad$ Mach number

$p \quad$ pressure $(\mathrm{Pa})$

$r \quad$ radial coordinate $(m)$

$T \quad$ total simulation time $(s)$

$t \quad$ time $(s)$

$W \quad$ width of the tunnel $(m)$

$Z \quad$ reduced distance, $Z=r / m_{c}^{1 / 3}\left(m / k g^{1 / 3}\right)$

$Z_{x} \quad$ position of transition zones between $3 \mathrm{D}$ and $2 \mathrm{D}$ patterns $(x=H)$, and between $2 \mathrm{D}$ and $1 \mathrm{D}$ patterns $(x=W) . Z_{W-H}=Z_{W}-Z_{H}\left(\mathrm{~m} / \mathrm{kg}^{1 / 3}\right)$

m weight $(k g)$

\section{Indices}

$0 \quad$ reference conditions

c explosive charge 
$H \quad$ height

$h \quad$ hydraulic

Trans transition

$W \quad$ width

\section{Introduction}

Blast wave is a topical research subject as shown by the several recent works $[10,12,11]$, and in particular confined blast wave $[18,5]$. One of the application of the confined domain is the underground network. Underground networks such as subway station have rectangular cross-section. Typically, the height is smaller than the width. Therefore, blast waves occurring in such a domain exhibit three patterns: (a) a free-field pattern, known to yield fast overpressure decay, while the blast wave does not reach any obstacle; (b) a two-dimensional (2D) pattern after the first reflection (vertical: in the direction of the height) and (c) a one-dimensional (1D) pattern after the second reflection (transversal: in the direction of the width). 2D and 1D patterns obviously induced lower overpressure decays involving more dramatical damages not only for the structures but also for the peoples. The knowledge of the global behavior of blast waves in such a confined domain is thus decisive for safety reasons.

The first pattern cited above, ie. the free-field pattern, is indubitably the most studied. From these studies, scaling laws were derived, as the laws 
from Baker, Cox, Westine, Kulesz and Strehlow [1], [15], [4] or [9] relating the maximum overpressure peak to the distance from the explosive charge. In fact, [9] proposed one of the most common free-field decay law, which is expressed as:

$$
\left\{\begin{array}{l}
\left.\frac{\Delta P_{\max }}{P_{\text {ref }}}\right|_{\text {Henrych }}=\frac{14.072}{Z}+\frac{5.54}{Z^{2}}-\frac{0.357}{Z^{3}}+\frac{0.00625}{Z^{4}} \text { if } 0.05 \leq Z \leq 0.3 \\
\left.\frac{\Delta P_{\max }}{P_{\text {ref }}}\right|_{\text {Henrych }}=\frac{6.194}{Z}-\frac{0.326}{Z^{2}}+\frac{2.132}{Z^{3}} \text { if } 0.3 \leq Z \leq 1 \\
\left.\frac{\Delta P_{\max }}{P_{\text {ref }}}\right|_{\text {Henrych }}=\frac{0.662}{Z}+\frac{4.05}{Z^{2}}+\frac{3.288}{Z^{3}} \text { if } 1 \leq Z .
\end{array}\right.
$$

The third propagation pattern is the case of a confined explosion, which considers that the blast wave propagates inside a confined space that is strong enough to withstand the explosive charge impulse (e.g., a tunnel). Among the few reported experiments investigating air detonation in underground environments, some gave overpressure decays laws during this third pattern. [6] proposed the following pressure-distance law for various explosives weights:

$$
\frac{\Delta p}{p_{0}}=\left(\frac{M}{\Phi^{2} x}\right)^{0.8} \text {. }
$$

[17] determined the following overpressure-distance decay relationship:

$$
\frac{\Delta p}{p_{0}}=7.028\left(\frac{M}{A r}\right)^{0.514} \text {. }
$$

Applying the energy concentration concept (ECF), which is detailed in section 2.3, [16] the very similar law:

$$
\frac{\Delta p}{p_{0}}=7.43538\left(\frac{M}{A r}\right)^{0.51} .
$$

[3] have investigated the position of the transition zone between the three-dimensional (3D) and the 1D patterns for a square cross-sectional tunnel. They performed detonations of charges ranging between $0.150 \mathrm{~kg}$ and 
$15.000 \mathrm{~kg}$ of trinitrotoluene (TNT) in a $5 \mathrm{~m}^{2}$ cross-sectional tunnel. Defining the ratio size $\alpha=100 d_{c} / d_{h}$, where $d_{c}$ was the charge diameter and $d_{h}$ was the hydraulic diameter of the tunnel. They shown the transition zone is located at :

$$
Z_{\text {trans }}=\frac{0.0509}{(\alpha / 100)^{13 / 9}} .
$$

However, in square cross-sectional tunnel the four Mach reflections (upper and lower in both transversal and vertical coordinates) occur at the same time producing a large pressure increase when the Mach reflections catch up the incident wave. The shape of the blast wave looks totally different in rectangular cross-sectional tunnel where transversal and vertical reflections do not occur simultaneously.

The objective of this paper is to determine the position of both the 3D$2 \mathrm{D}$ and the 2D-1D transition zones and to predict the overpressure occurring in these three zones. To accomplish this, the detonation of different quantities of TNT explosives inside a perfectly rigid tunnel was simulated. The following section presents the geometrical configuration, the numerical methodology and the ECF method. Moreover, scaling laws that eliminates the solution's parametric dependence on the explosive energy, the weight of the explosives and the real tunnel cross-sectional size are provided. These scaling laws transform the infinite number of solutions into a single solution that demonstrates a monotonic transition from one wave pattern to another pattern. Afterwards, the numerical results are brought in section 3. These numerical results consisted of overpressure history for different widths and 
heights of the cross-section, and of different detonation mass. In section 4, fitting power law are proposed to estimate the locations of both transition zones. Furthermore, an algorithm giving the complete map of the overpressure pattern is introduced. This algorithm is validated by comparison with previous experimental data.

\section{Configurations, numerical details and ECF method}

\subsection{Calculation domains and non-dimensional numbers}

The calculation domains are presented in figure 1. They consist on rectangular cross-sectional tunnel of length $L=25 \mathrm{~m}$. The cross-sectional widths and heights ranged from 3 to 7 meters and 2 to 5 meters respectively. Especially, a square cross-sectional tunnel of $3 \mathrm{~m}^{2}$ area was considered to verify

results from [3]. In order to study the effect of the width, four additional configurations with $3 \mathrm{~m}$ height and width ranging from 4 to $7 \mathrm{~m}$ are investigated. A $6 \mathrm{~m}$ width and $2 \mathrm{~m}$ height domain is considered because it yields the same hydraulic diameter as the $3 \mathrm{~m}$ side square section. Then, two additional configurations with $6 \mathrm{~m}$ width and respectively 4 and $5 \mathrm{~m}$ height are studied to evaluate the effect of the height. Furthermore, TNT charge ranging from 1.000 to $10.000 \mathrm{~kg}$ are investigated.

It can be anticipated that the first reflection modifying the 3D shape of the blast wave in a 2D shape depends on the height of the domain $H$. Therefore a first parameter $\alpha_{H}$, inspired by the work of [3] is considered: 


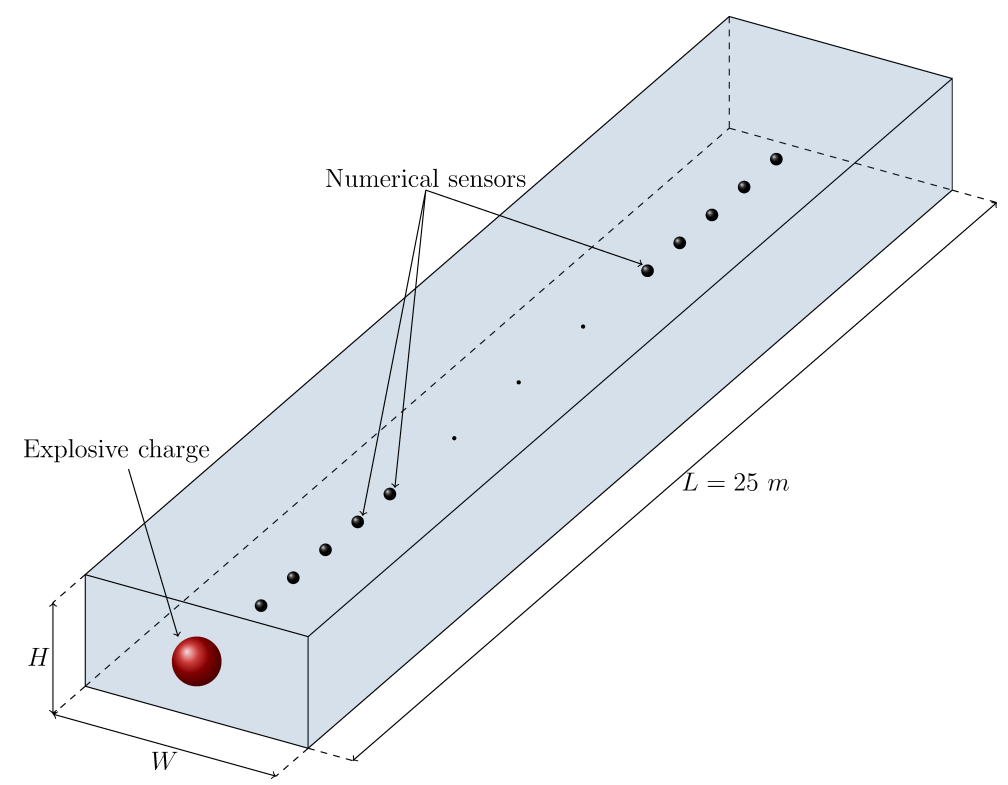

Figure 1: Calculation domains.

$$
\alpha_{H}=100 \frac{d_{c}}{H}
$$

In the same way, the difference between the second and the first reflection modifying the $2 \mathrm{D}$ shape of the bast wave in a $1 \mathrm{D}$ shape depends on difference between the width, $W$, and the height of the domain. Thus, a second parameter is:

$$
\alpha_{W-H}=100 \frac{d_{c}}{W-H} .
$$

The parameter $\alpha_{W}$ based on the width of the domain will also be used 
for convenience.

The numerical results are highlighted by the pressure coefficient defined as:

$$
C_{p}=\frac{p-p_{0}}{p_{0}}
$$

\subsection{Numerical details}

1D calculation was performed as long as the incident blast wave did not encounter any obstacle. This strategy obviously yield a faster and more accurate computations. During this 1D calculation, the TNT gases, composed of hot detonation products, obey the Jones-Wilkins-Lee law, which is expressed by $[14]$ :

$$
p=A\left(1-\frac{\omega}{R_{1}} \frac{\rho}{\rho_{c}}\right) \exp \left(-R_{1} \rho_{c} / \rho\right)+B\left(1-\frac{\omega}{R_{2}} \frac{\rho}{\rho_{c}}\right) \exp \left(-R_{2} \rho_{c} / \rho\right)+\omega \rho e,
$$

where the parameters $A, B, R_{1}, R_{2}, \omega$ and $\rho_{c}$ depend on the explosive material. Table (1) provides these parameters. Details of the 1D solver, as well as the 1D-3D transfer method are available in [2]. The same 1D calculation was used for all configurations.

The initial condition for the 3D calculation, thus the result of the $1 \mathrm{D}$ calculation, was located in the center of the cross-section, see figure 1, using a symmetry condition in the longitudinal axis. 
Table 1: Parameters used for the JWL law describing the T.N.T. explosive material $\begin{array}{lllllll}\text { Specific } & \text { Density, } & A & B & R_{1} & R_{2} & \omega\end{array}$ energy, $e_{c} \quad \rho_{\mathbf{c}}$

\begin{tabular}{lllllll}
\hline$k J / k g$ & $k g / m^{3}$ & $10^{11} \mathrm{~Pa}$ & $10^{9} \mathrm{~Pa}$ & - & - & - \\
\hline 4870 & 1580 & 3.73 & 3.74 & 4.15 & 0.90 & 0.35 \\
\hline
\end{tabular}

Blast wave propagation is governed by the unsteady Euler equations, which were solved by a proprietary software [2]. The numerical method on which this software's solver is based is a unstructured finite-volume cellcentered approach using the traditional upwind scheme and a two-stage explicit time integration technique, yielding a second-order accuracy in both space and time. In order to prevent numerical oscillations, which may occur in regions with strong gradients, the Total Variation Diminishing (TVD) minmod scheme is used [13]. The spatial discretization is performed with an automatic Cartesian grid generator [7]. In addition, the Courant-FriedrichsLewy (CFL) condition has to be satisfied in order to guarantee the stability of the time integration technique. The successive gauges, also centered into the cross-section, were located $0.2 \mathrm{~m}$ from each other knowing that the first one was $1 \mathrm{~m}$ from the explosive charge.

The initial computational domains are split into $0.5 \mathrm{~m}$ cube elements and a dynamic adaptive mesh method was applied to finely catch the incident wave: the refinement criterion was based on the density value. A fine mesh 
was kept after the incident wave passage to guarantee an accurate prediction of the complex waves pattern following the incident wave. The averaged number of elements was ranged from $4 \times 10^{6}$ for the smallest domain to $10^{7}$ for the largest one. The smallest refined elements were $1.5 \times 10^{-2} \mathrm{~m}$ ensuring a mesh wave number $\lambda$ of 67, 106, 128 and 144 for the TNT charges of $1.000,4.000,7.000$ and $10.000 \mathrm{~kg}$, respectively. The mesh wave number has to satisfy in the ideal case $\lambda>100[2]$.

\subsection{The concept of Energy Concentration Factor}

The concept of energy concentration factor introduced by Silvestrini et al. [16] is adapted in the present paper. The idea is to scale the abscissa of freefield decay law, for instance Henrych's law (1), by geometrical consideration. As shown in figure 2, for the same volume the cylinder shape blast wave (2D) has a radius $R^{\prime}$ defined as $R^{\prime}=\sqrt{4 R^{3} / 3 W}$ where $R$ is the radius of the equivalent spherical shape blast wave $(3 \mathrm{D})$. Then, the new scale distance is:

$$
Z^{\prime}=\frac{R^{\prime}}{M_{c}^{1 / 3}}=\sqrt{\frac{4 Z^{3} M_{c}^{1 / 3}}{3 W}} .
$$

It has to be noted that the ECF method was essentially developed and validated for $3 \mathrm{D}$ to $1 \mathrm{D}$ transition. Therefore, one objective of the present paper is to see whether the ECF method is available for $3 \mathrm{D}$ to $2 \mathrm{D}$ transition.

\section{Results and discussion}

\subsection{Effects of the width, $\alpha_{H}=3.55, M_{c}=1.000 \mathrm{~kg}$}

Figure 3 shows the distribution of the overpressure peak of the incident wave for $\alpha_{H}=3.55$ (typically $H=3 \mathrm{~m}$ and $M_{c}=1.000 \mathrm{~kg}$ ). The square 


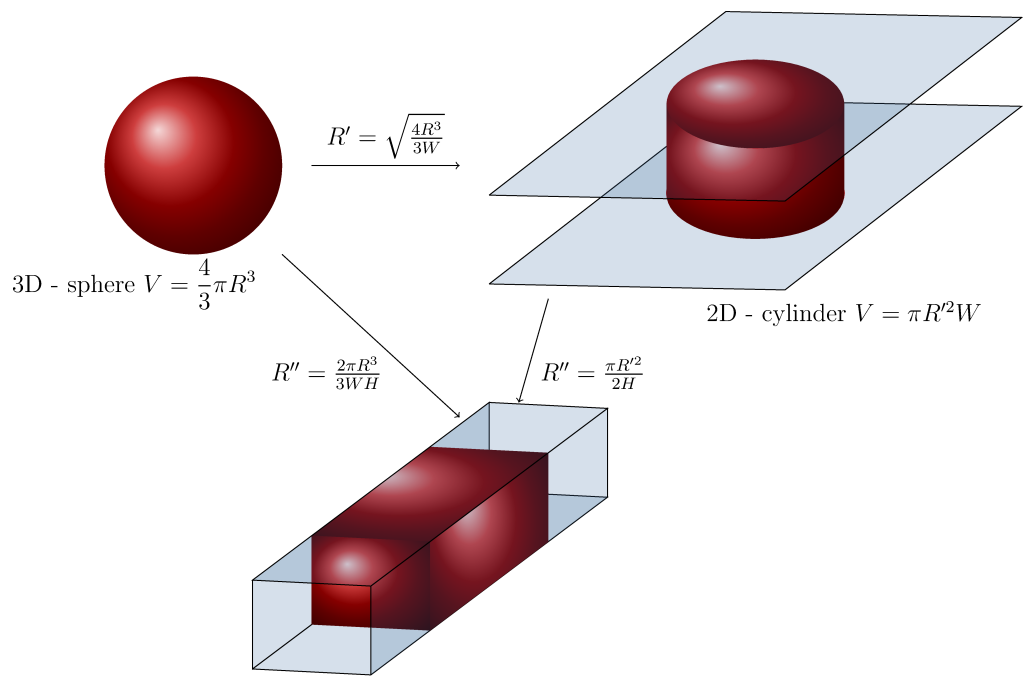

$1 \mathrm{D}$ - rectangle parallelepiped $V=2 R^{\prime \prime} W H$

Figure 2: Scaling used for the ECF method.

section and rectangular sections with $\alpha_{W-H}$ ranging from infinity to 10.64 were investigated. The numerical results are compared with 3D law, and 2D and 1D laws calculated with the ECF method for $\alpha_{W}=\alpha_{H}=3.55$, then $\alpha_{W-H}=\infty$. As can be seen, the square configuration $\left(\alpha_{W-H}=\infty\right)$ produced an unique jump while rectangular configurations yield two jumps corresponding to the height reflection and the width reflection. The first jump occurred at the same location for every rectangular configurations, slightly after the square jump, showing the first reflection is only function of the height. The slight delay cited above is because the Mach reflection in the square section is composed of four parts (two for both the width and 


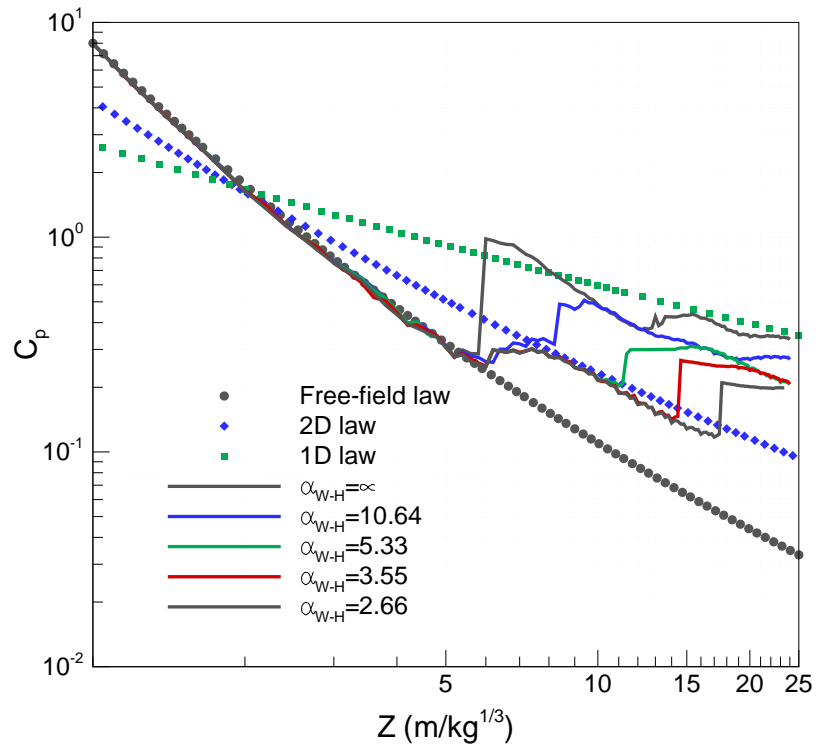

Figure 3: Distribution of the maximum pressure over the axial gauges for different domain height, $\alpha_{H}=3.55, M_{c}=1.000 \mathrm{~kg}$. $2 \mathrm{D}$ and $1 \mathrm{D}$ laws were calculated on $\alpha_{W-H}=\infty$.

the height) and is thus stronger, and then faster, than the height reflection of rectangular configurations. It is shown that after the height reflection and before the width reflection, the overpressure peak of every rectangular configurations follow the same law which is very close to the 2D law determined by the ECF method. Finally, after the width reflection, the overpressure peaks show different patterns. Nevertheless, 1D law calculated from ECF method gives a good representation of the configuration $\alpha_{W-H}=\infty$ especially after $Z=13 \mathrm{~m} / \mathrm{kg}^{1 / 3}$. 


\subsection{Effects of the height, $\alpha_{W}=1.77, M_{c}=1.000 \mathrm{~kg}$}

Figure 4 shows the distribution of the overpressure peak of the incident wave for,$\alpha_{H}$ ranging from 1.95 to 5.33. The numerical results are compared with 3D law, and 2D and 1D laws calculated with the ECF method on the configuration $\alpha_{H}=5.33$. For the configuration $\alpha_{H}=1.95$, both reflections are too close. It means the width reflection has too large impact on the height reflection and strengthens it. Therefore, the incident wave becomes almost immediately one-dimensional. 2D and $1 \mathrm{D}$ laws seem to perfectly match the numerical result of $\alpha_{H}=5.33$ but are totally different to other configurations. However, the $2 \mathrm{D}$ pattern of the configuration $\alpha_{H}=5.33$ seems to go towards the $2 \mathrm{D}$ pattern of the configuration $\alpha_{H}=3.55$ before $Z=7 \mathrm{~m} / \mathrm{kg}^{1 / 3}$. In the same way, the 2D pattern of the configuration $\alpha_{H}=3.55$ seems to go towards the $2 \mathrm{D}$ pattern of the configuration $\alpha_{H}=2.66$. These two observations yield the conclusion that the overpressure peak does not depend on the height.

\subsection{Effects of the charge of the mass}

Figure 5 shows the distribution of the overpressure peak of the incident wave for mass of the charge ranging from $1.000 \mathrm{~kg}$ to $10.000 \mathrm{~kg}$. Every calculation were done on the same domain, $W=6 \mathrm{~m}$ and $H=2 \mathrm{~m}$. The numerical results are compared with $3 \mathrm{D}$ law, and 2D and 1D laws calculated with the ECF method on $\alpha_{H}=11.15$ and $\alpha_{W-H}=5.73$, ie. for a charge of $10.000 \mathrm{~kg}$. The main information in figure 5 is that 2D patterns are the same for every mass. Configurations $\alpha_{H}=11.15, \alpha_{H}=10.19$ and $\alpha_{H}=8.45$ clearly have overpressure peaks superimposed between both jumps. Furthermore, the 2D pattern of $\alpha_{H}=5.33$ seems to be the continuity of the three configurations 


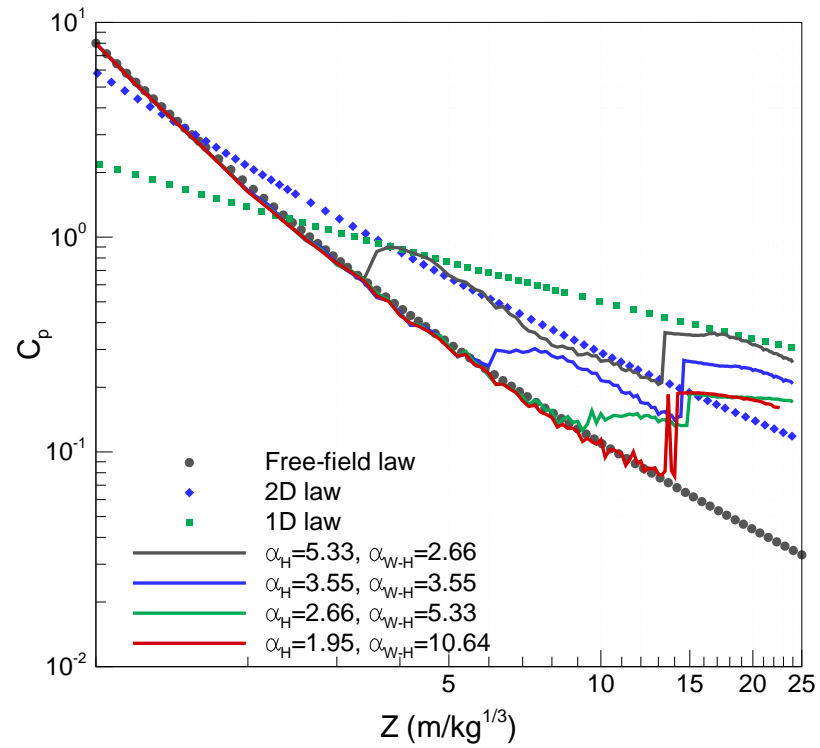

Figure 4: Distribution of the maximum pressure over the axial gauges for different domain height, $\alpha_{W}=1.77, M_{c}=11.000 \mathrm{~kg} .2 \mathrm{D}$ and $1 \mathrm{D}$ laws were calculated on $\alpha_{H}=5.33$.

cited above.

The 1D law developed from ECF method well predicts the 1D pattern of $\alpha_{H}=11.15$. However, figure 5 shows the disability of the ECF method to predict the overpressure peak during the $2 \mathrm{D}$ behavior of the wave when the first reflection is occurring quickly, e.g. for a low value of $\mathrm{Z}$. 


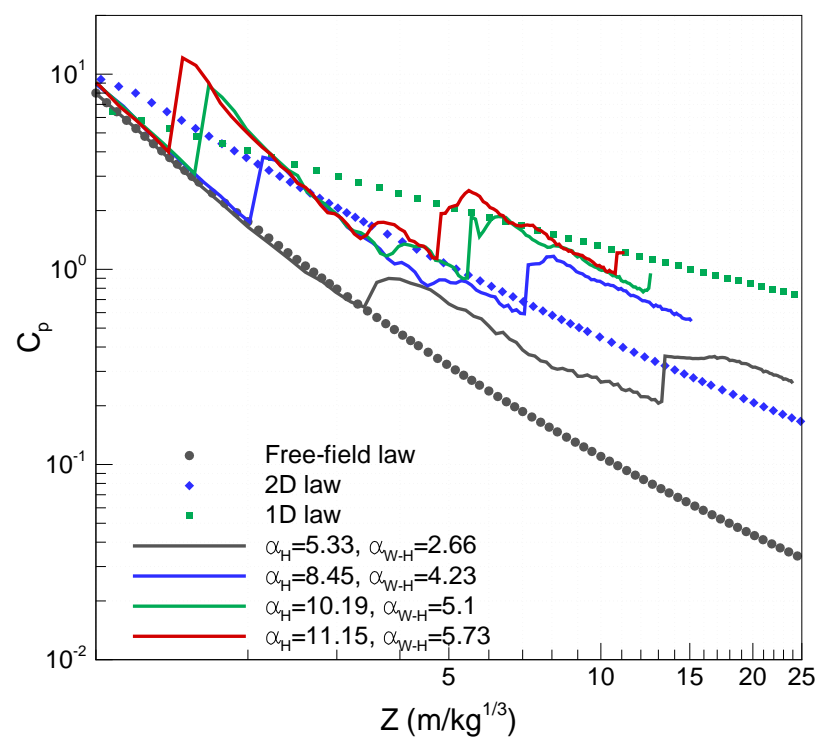

Figure 5: Distribution of the maximum pressure over the axial gauges for different mass of the charge. 2D and 1D laws were calculated with $\alpha_{H}=11.15$ and $\alpha_{W-H}=5.73$.

\section{Determination of $Z_{H}, Z_{W}$ and the overpressure peak value in}

\section{$2 \mathrm{D}$ and $1 \mathrm{D}$}

The results of the previous sections have shown the ECF method is particularly accurate for the 1D pattern of blast waves. It has been also shown that this method is not suitable for the $2 \mathrm{D}$ pattern especially for high value of $\alpha_{H}$. However, it has been proved that the 2D pattern of the incident blast wave is the same for every configurations. Therefore, a polynomial interpolation, as the one of equation (1) can be proposed. Finally, knowing the transition locations, $Z_{H}$ and $Z_{W}$, the complete incident wave pattern can be 
deduced.

Figure 6 shows the distributions of the discontinuity locations $Z_{H}$ and $Z_{W-H}=Z_{W}-Z_{H}$ versus $\alpha_{H}$ and $\alpha_{W-H}$, respectively. It is shown both discontinuity locations depend linearly on the parameter $\alpha$. Using the leastsquare algorithm, best correlations are gave by:

$$
Z_{H}=\frac{0.07992}{\left(\alpha_{H} / 100\right)^{1.317}}
$$

and

$$
Z_{W-H}=\frac{0.07994}{\left(\alpha_{W-H} / 100\right)^{1.351}} .
$$

The first fit has a correlation coefficient of 0.999, while the second one has a correlation factor of 0.971 . Actually, it even sounds possible to use a common power fit for both discontinuity locations. Finally, it has to be said that these laws are close to the law giving the transitional zone 3D-1D (5) found in [3] for square sections.

Interpolating the clearest points of $2 \mathrm{D}$ patterns superimposition gives the 2D law:

$$
\left(C_{p}\right)_{2 D}=\frac{33.78}{Z^{3}}+\frac{3.74}{Z^{2}}+\frac{1.52}{Z} .
$$

Finally the algorithm of calculation of the overpressure peak can, then, be written as:

1. calculate $Z_{H}=\frac{0.07992}{\left(\alpha_{H} / 100\right)^{1.317}}$, 


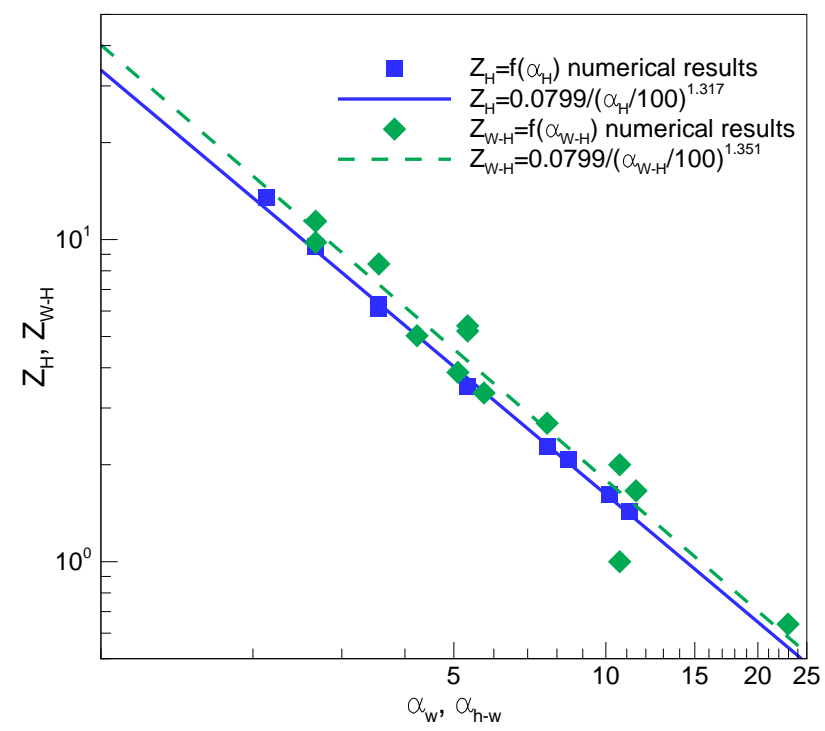

Figure 6: Discontinuity locations $Z_{H}$ and $Z_{W-H}$ as functions of $\alpha_{H}$ and $\alpha_{W-H}$.

2. for $Z \leq Z_{H}$, the pressure is given by (1),

3. calculate $Z_{W}=Z_{H}+\frac{0.07994}{\left(\alpha_{W-H} / 100\right)^{1.351}}$,

4. for $Z_{H}<Z \leq Z_{W}$, the pressure is given by (12),

5. for $Z>Z_{W}, Z^{\prime}=\left(\frac{3 Z W H}{2 \pi}\right)^{1 / 3}$,

6 . for $Z^{\prime}$, the pressure is given by (1).

\section{Validation of the algorithm}

Validation is done by comparison with experimental data from a series of trials carried out by INERIS (French Institute of Industrial Environment and Risks) and already presented in [3]. The trial used in the present pa- 


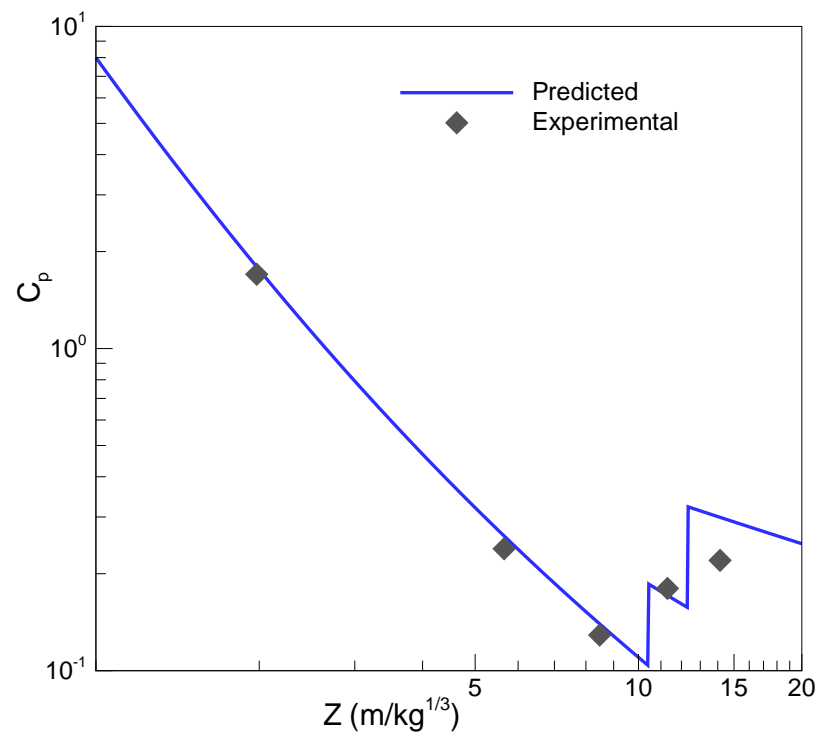

Figure 7: Comparison between experimental data and predicted value of pressure peak.

per concerns on the detonation of $0.300 \mathrm{~kg}$ of NP91 in the center of $80 \mathrm{~m}$ length mine tunnel with an averaged rectangular cross-section of $3.5 \times 3 \mathrm{~m}^{2}$. Based on the maximum pressure effect $[8,19]$, the TNT equivalence factor was found to be 1.18. In the experimental setup, 5 sensors located every $2 \mathrm{~m}$ from the charge were considered.

Figure 7 shows the peak of overpressure of the incident wave for the experimental data and the predicted map done by the algorithm. It is shown the predicted pressure is in good convenience with experimental data. The transition zones are correctly determined by the algorithm. Moreover, the values of experimental pressure peak are well fitted by the predicted pressure. 


\section{Conclusion}

Numerical computations are carried out to predict the locations of the 3D-2D transition and the 2D-1D transition of a blast wave in a rectangular cross-sectional tunnel. In order to avoid any lack of generality, different width and height domains as well as different charge of mass were investigated. The numerical results were compared to free-field law and to the ECF method for the $2 \mathrm{D}$ and the $1 \mathrm{D}$ patterns.

The main results of this work are:

- the 3D-2D transition is only a function of $\alpha_{H}$

- as soon as the wave became $2 \mathrm{D}$, the transition to the $1 \mathrm{D}$ pattern is only a function of $\alpha_{W-H}$

- the ECF method is suitable to predict the overpressure of the $2 \mathrm{D}$ pattern for the lower value of $\alpha_{H}$

- a polynomial function is proposed to predict the overpressure peak of the $2 \mathrm{D}$ pattern to provide the lacks of the ECF method for high value of $\alpha_{H}$

- the ECF method is suitable to predict the overpressure of the 1D pattern

An algorithm has been proposed to efficiently predict the overpressure pattern. This algorithm has been validated by comparison with experimental data. This algorithm may be very helpful to efficiently drawing up the blast wave damages. 


\section{Acknowledgments}

This research was carried out for the TRISTAN project, supported by the French National Research Agency (ANR).

\section{References}

[1] Baker, W.E., Cox, P.A., Westine, P.S., Kulesz, J.J., Strehlow, R.A., 1983. Explosion hazards and evaluation. Fundamental studies in engineering. Elsevier, New-York.

[2] Benselama, A., William-Louis, M.P., François, M., 2009. A 1D-3D mixed method for the numerical simulation of blast waves in confined geometries. J. Comupat. Phys. 228, 6796-6810.

[3] Benselama, A.M., William-Louis, M.J.P., Monnoyer, F., Proust, C., 2010. A numerical study of the evolution of the blast wave shape in tunnels. Journal of Hazardous Materials 181, $609-616$.

[4] Brode, H.L., 1959. Blast waves from a spherical charge. Phys. Fluids 2, $217-229$.

[5] Buonsanti, S., Leonardi, G., 2013. 3-D simulation of tunnel structures under blast loading. Archives of Civil and Mechanical Engineering 13, $128-134$.

[6] Curran, D., 1996. Underground storage of ammunition - experiments concerning accidental detonation in an underground chamber. Technical Report. Norwegian Defense Research Establishment. 
[7] Deister, F., Waymel, F., Hirschel, E., Monnoyer, F., 2002. Selforganizing hybrid cartesian grid generation and application to external and internal flows, numerical flow simulation III. Notes on Num. Fluid Mech. Des. 82, 1829.

[8] Formby, S., Wharton, R., 1996. Blast characteristic and TNT equivalence values for some commercial explosives detonated at ground level. J. Hazard. Mater. 50, 183-198.

[9] Henrych, J., 1979. The dynamics of explosion and its use. Elsevier Press, Amsterdam.

[10] Igra, O., Falcovitz, J., Houas, L., Jourdan, G., 2013. Review of methods to attenuate shock/blast waves. Progress in Aerospace Sciences 58, 1 35.

[11] Kim, W., Mogi, T., Dobashi, R., 2014. Effect of propagation behaviour of expanding spherical flames on the blast wave generated during unconfined gas explosions. Fuel 128, 396 - 403.

[12] Langlet, A., William-Louis, M., Girault, G., Pennetier, O., 2014. Transient response of a plate-liquid system under an aerial detonation: Simulations and experiments. Computers \& Structures 133, 18 - 29.

[13] van Leer, B., 1979. Towards the ultimate conservative scheme, V. A second-order sequel to Godunov's method. J. Comput. Phys. 32, 101136.

[14] Mader, C., 1998. Numerical modeling of explosives and propellants. 2nd edition ed., Univ. California Press. 
[15] Mills, C., 1987. The design of concrete structures to resist explosions and weapons effects, Edinburgh, UK.

[16] Silvestrini, M., Genova, B., Leon Trujillo, F., 2009. Energy concentration factor. A simple concept for the prediction of blast propagation in partially confined geometries. J. Loss prevent. Proc. 22, 449-454.

[17] Smith, A., Sapko, M., 2005. Detonation wave propagation in underground mine entries. J. Mine Vent. Soc. South Africa .

[18] Song, M., Ge, S., 2013. Dynamic response of composite shell under axial explosion impact load in tunnel. Thin-Walled Structures 67, 49 - 62 .

[19] Wharton, R., Formby, S., Merrifield, R., 2000. Air blast TNT equivalence for a range of commercial blasting explosives. J. Hazard. Mater. $79,31-39$. 


\section{List of Tables}

1 Parameters used for the JWL law describing the T.N.T. explosive material . . . . . . . . . . . . . . . . . 10 


\section{List of Figures}

1 Calculation domains. . . . . . . . . . . . . 8

2 Scaling used for the ECF method. . . . . . . . . . . . . 12

3 Distribution of the maximum pressure over the axial gauges for different domain height, $\alpha_{H}=3.55, M_{c}=1.000 \mathrm{~kg}$. $2 \mathrm{D}$ and 1D laws were calculated on $\alpha_{W-H}=\infty \ldots \ldots . \ldots 13$

4 Distribution of the maximum pressure over the axial gauges for different domain height, $\alpha_{W}=1.77, M_{c}=11.000 \mathrm{~kg}$. $2 \mathrm{D}$ and 1D laws were calculated on $\alpha_{H}=5.33 \ldots \ldots \ldots$

5 Distribution of the maximum pressure over the axial gauges for different mass of the charge. 2D and 1D laws were calculated with $\alpha_{H}=11.15$ and $\alpha_{W-H}=5.73 \ldots \ldots \ldots . . . \ldots 16$

6 Discontinuity locations $Z_{H}$ and $Z_{W-H}$ as functions of $\alpha_{H}$ and $\alpha_{W-H} \ldots \ldots \ldots \ldots \ldots \ldots \ldots \ldots$

7 Comparison between experimental data and predicted value of pressure peak. . . . . . . . . . . . . . . . . 19 